\title{
GARNET - gene set analysis with exploration of annotation relations
}

\author{
Kyoohyoung Rho ${ }^{1,4 \dagger}$, Bumjin Kim²,3† , Youngjun Jang ${ }^{1,4 \dagger}$, Sanghyun Lee ${ }^{3}$, Taejeong Bae ${ }^{1,4}$, Jihae Seo ${ }^{2,3}$, \\ Chaehwa Seo ${ }^{2,3}$, Jihyun Lee ${ }^{1,4}$, Hyunjung Kang ${ }^{2,3}$, Ungsik Yu ${ }^{5}$, Sunghoon Kim ${ }^{1,4}$, Sanghyuk Lee ${ }^{2,3}$, Wan Kyu Kim²,3*
}

From The Ninth Asia Pacific Bioinformatics Conference (APBC 2011)

Inchon, Korea. 11-14 January 2011

\begin{abstract}
Background: Gene set analysis is a powerful method of deducing biological meaning for an a priori defined set of genes. Numerous tools have been developed to test statistical enrichment or depletion in specific pathways or gene ontology $(\mathrm{GO})$ terms. Major difficulties towards biological interpretation are integrating diverse types of annotation categories and exploring the relationships between annotation terms of similar information.

Results: GARNET (Gene Annotation Relationship NEtwork Tools) is an integrative platform for gene set analysis with many novel features. It includes tools for retrieval of genes from annotation database, statistical analysis \& visualization of annotation relationships, and managing gene sets. In an effort to allow access to a full spectrum of amassed biological knowledge, we have integrated a variety of annotation data that include the GO, domain, disease, drug, chromosomal location, and custom-defined annotations. Diverse types of molecular networks (pathways, transcription and microRNA regulations, protein-protein interaction) are also included. The pair-wise relationship between annotation gene sets was calculated using kappa statistics. GARNET consists of three modules - gene set manager, gene set analysis and gene set retrieval, which are tightly integrated to provide virtually automatic analysis for gene sets. A dedicated viewer for annotation network has been developed to facilitate exploration of the related annotations.

Conclusions: GARNET (gene annotation relationship network tools) is an integrative platform for diverse types of gene set analysis, where complex relationships among gene annotations can be easily explored with an intuitive network visualization tool (http://garnet.isysbio.org/ or http://ercsb.ewha.ac.kr/garnet/).
\end{abstract}

\section{Background}

Omics studies usually yield a number of gene lists e.g. differentially expressed genes (DEGs). Typically, a statistical test of enrichment or depletion is performed for an a priori defined set of genes (usually from clustering of microarray data) or gene annotations. This approach has been successfully applied for diverse subjects including gene ontology (GO), signalling and metabolic pathways, and identification of regulatory elements such as transcription factors and microRNAs. However, biological

\footnotetext{
* Correspondence: wkim@ewha.ac.kr

† Contributed equally

${ }^{2}$ Division of Molecular Life Sciences, Ewha Womans University, Seoul 120-

750, Korea

Full list of author information is available at the end of the article
}

interpretation of gene lists is still a challenge for many biologists because there is no 'golden standard method' established yet. Numerous annotation DBs and tools have been developed for biological interpretation of experimental gene lists including but not limited to GSEA [1], DAVID [2], Gazer [3], FatiGO+ [4], g:Profiler [5], WebGestalt [6] Lists2Networks [7] and GOAL [8]. A comprehensive list of 68 GSA web tools is recently reviewed by Huang et al [9] as well as several important points to consider in using such tools. As Huang and colleagues suggests, each tool has its own strength and limitations in terms of statistical method, coverage of gene annotation types and user interface [9].

One important issue in the field is the growing complexity of annotation data themselves. The benefit of
C Biomed Central

() 2011 Rho1 et al; licensee BioMed Central Ltd. This is an open access article distributed under the terms of the Creative Commons Attribution License (http://creativecommons.org/licenses/by/2.0), which permits unrestricted use, distribution, and reproduction in any medium, provided the original work is properly cited. 
gene set analysis (GSA) mainly comes from the power to summarize hundreds or even thousands of genes into a smaller number of enriched biological themes e.g. GO term or pathways, allowing simplified interpretation of high-throughput experiments. However, the analytic complexity of GSA is getting beyond its benefits because of the rapid increase of gene annotations e.g. a few dozens of genes can be enriched in a hundred or more annotation terms. The number of GO terms is already more than the number of genes in a human genome and the situation is getting similar with other types of annotation like pathways, the regulatory targets of TFs and miRNA, disease-associated genes and chromosomal locations even without considering their combinations [10]. Increasingly, omics data continue to be sources of new annotations e.g. cancer signature genes from microarray [11] and disease-associated genes from GWAS studies [12]. Major difficulties towards meaningful biological interpretation are integrating diverse types of annotations and at the same time, handling the complexities for efficient exploration of annotation relationships.

GARNET (Gene Annotation Relationship Network Tools) is an integrative platform for diverse types of gene set analysis, allowing convenient annotation network navigation. The utility of GARNET is two-fold. One is to facilitate the interpretation of gene sets from high-throughput experiments such as microarray, ChIPchip (ChIP-Seq) and high-throughput screening. The other is to serve as a framework for meta-analysis of heterogeneous annotations and pre-existing knowledge, which often lead to novel insights undetectable by individual analyses [13]. In an effort to allow access to a full spectrum of amassed biological knowledge, we have integrated a variety of annotation data that include the $\mathrm{GO}$, domain, disease, drug, chromosomal location, and custom-defined annotations. Diverse types of molecular networks (pathways, transcription and microRNA regulations) are also included. To deal with the complexity from a large number of annotations from different categories, a dedicated annotation network viewer has been developed for the visualization of related annotations.

GARNET system consists of three modules - gene set retrieval tool, gene set manager tool, and gene set analysis tool, which are tightly integrated to allow access, manipulation and statistical analysis of pre-compiled gene annotations and user-defined gene lists. The relationship between annotation terms is calculated using Cohen's kappa statistic. Kappa is less sensitive to the gene set size than other P-value statistics such as Chi-square, hypergeometric and binomial test because it measures the difference between the observed and the expected agreement between two annotation terms.

\section{Construction and content}

\section{System overview}

Considering highly exploratory nature of gene set analysis, GARNET is designed to navigate different layers of gene annotations in a convenient and integrated environment, equipped with ID conversion module, an interactive network viewer and import/export of any gene sets. GARNET contains four major groups of gene annotation information - molecular network, gene function, gene expression, and disease \& drugs (Figure 1a). Molecular network data include pathways, protein-protein interactions, and microRNA targets from several different sources. We also included gene annotation data such as gene ontology, protein domain and chromosomal location as well as differentially expressed genes (DEGs) from gene expression data. Gene-disease and gene-drug associations are also complied from relevant sources [14]. Further, any user-defined gene annotation data can be uploaded and analyzed against all the annotations in the system. The detailed scope of annotation data is provided in Table 1 and on-line.

The GARNET system consists of three main tools manager, analysis, and retrieval tools. Figure 1(b) shows the workflow of GARNET analysis. Users define gene sets using the manager tool where the set operation is available to combine two gene sets as union, intersection, and subtraction. The analysis tool performs enrichment test for the user-supplied genes in the annotation categories of choice. Multiple test correction is applied by default since there are so many annotation terms. The result of statistical analysis is given in table format where one can access the network view of annotation terms. In addition to the flat table view, GARNET also supports the tree view for hierarchical annotations such as GO and OMIM disease terms. The retrieval tool allows users to access the annotation database to extract genes assigned to any annotation term. Importantly, users may expand their gene list using the molecular networks in the annotation database. This novel feature allows users to investigate the down-stream effects of their genes of interest.

Any gene set analysis requires an ID system. We chose the Entrez geneID as the reference ID system instead of devising our own. This alleviates the maintenance (update \& expansion) problem significantly since most annotation databases provide the cross-reference to the Entrez geneID. GARNET supports most major gene IDs including Entrez Gene ID, Ensembl Ids (Gene, Transcript), GenBank, RefSeq, UniProt and microarray probe IDs (Affymatrix, Illumina). The detailed list of supported ID types is listed in Table 2. Even though we support diverse ID types for input, all subsequent 
a)

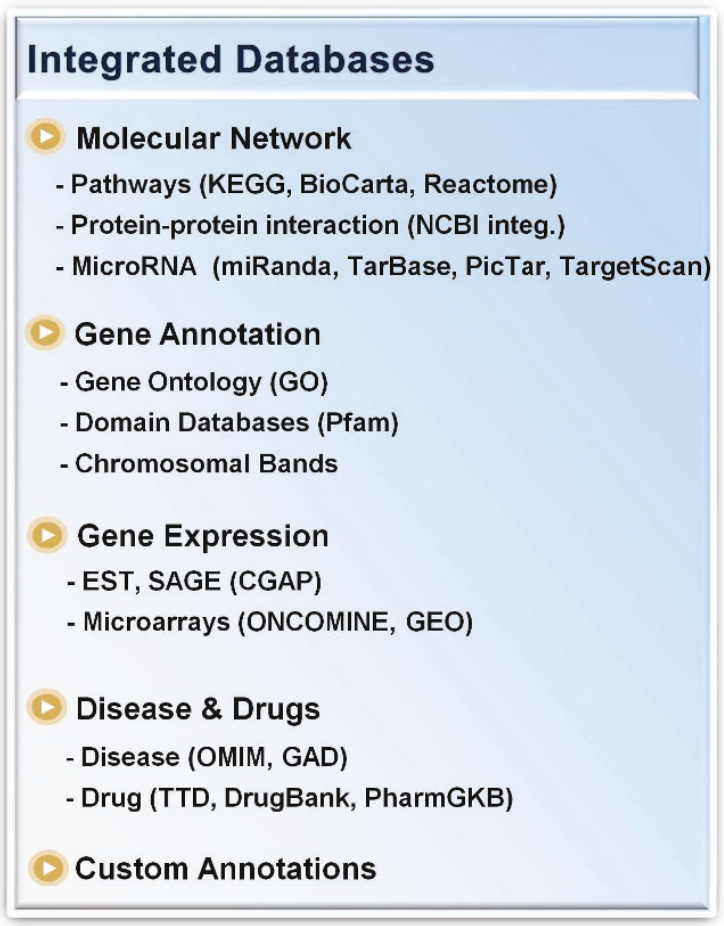

b)

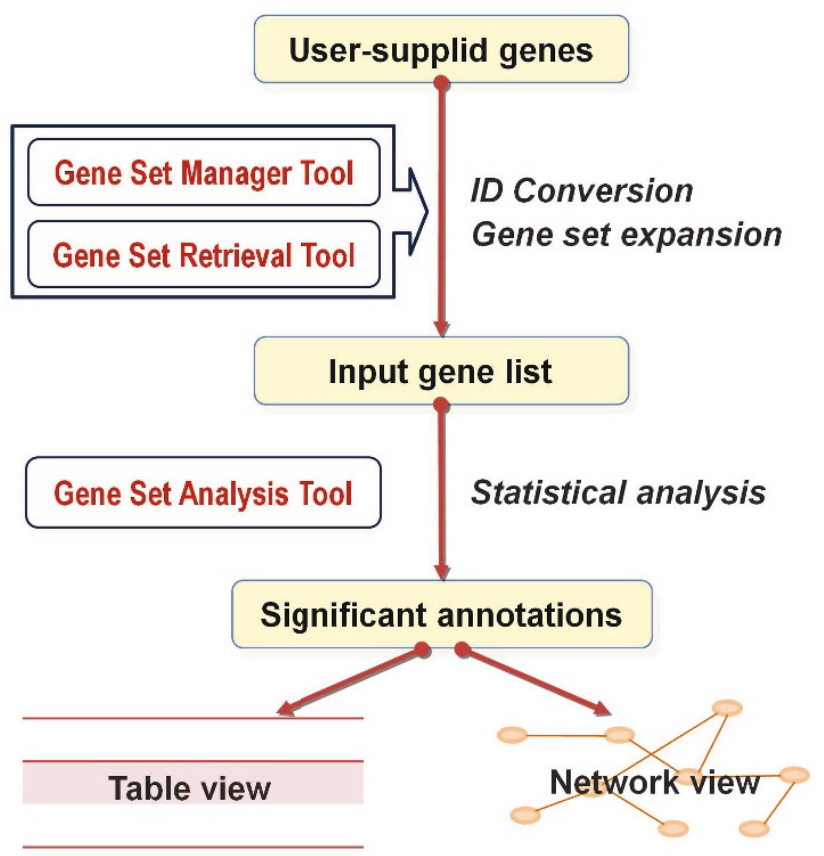

Figure 1 GARNET system overview. a) The annotation categories and types integrated in the GARNET system. b) The schematic overview of the workflow. The three main modules in the GARNET system are Gene Set Manager Tool, Retrieval Tool and Analysis Tool. The user-supplied genes are converted to standard gene IDs (Entrez Gene ID) by Manager Tool. A Gene set can be expanded via biological networks in Retrieval Tool. Analysis Tool performs gene set analysis (GSA) against the GARNET annotations selected by the user.

Table 1 Summary of the annotation categories and types in the GARNET system

\begin{tabular}{|c|c|c|c|c|c|}
\hline Category & Annotation DB & Number of Annotations & Number of Unique Genes & Version & Update Date \\
\hline \multirow[t]{8}{*}{ Molecular Network } & KEGG & 199 & 5193 & Release $54.0+/$ & 2010.05 .10 \\
\hline & BioCarta & 314 & 1383 & & 2010.04 .06 \\
\hline & Protein-Protein Interactions (PPI) & 5829 & 7631 & NCBI integrated DB & 2010.05 .17 \\
\hline & miRBase & 711 & 34525 & 5.0 & 2009.09.29 \\
\hline & TarBase & 106 & 394 & V5 & 2008.06 \\
\hline & TargetScan & 162 & 7930 & 4.2 & \\
\hline & PicTar-4way & 178 & 9152 & hg17, Build 35 & \\
\hline & PicTar-5way & 130 & 3455 & hg17, Build 35 & \\
\hline \multirow[t]{3}{*}{ Genome Annotation } & Gene Ontology (GO) & 30479 & 18242 & & 2010.05 .20 \\
\hline & Pfam domains & 3922 & 16409 & 24.0 & 2009.10.07 \\
\hline & Chromosomal Bands & 3078 & 32920 & & 2010.05 .23 \\
\hline \multirow[t]{4}{*}{ Gene Expression } & Tissue EST & 51 & 13367 & & 2010.04 .06 \\
\hline & Tissue SAGE & 32 & 8528 & & 2010.04 .06 \\
\hline & Tissue Microarray & 32 & 10769 & & \\
\hline & Cancer Microarray & 25 & 13619 & & \\
\hline \multirow[t]{3}{*}{ Disease \& Drug } & OMIM & 1063 & 2683 & & 2008.08 .27 \\
\hline & GAD & 1212 & 2872 & & 2008.12 .26 \\
\hline & DrugBank & 591 & 259 & & \\
\hline Total & & 57973 & 32920 & & \\
\hline
\end{tabular}


Table 2 List of supported ID types in GARNET

\begin{tabular}{cll}
\hline Category & \multicolumn{1}{c}{ ID Type } & \multicolumn{1}{c}{ Examples } \\
\hline Gene ID & Entrez Gene & 1457, 2002, 1950 \\
& Ensembl Gene & ENSG000000101266 \\
& Ensembl Transcript & ENST00000361797 \\
& GenBank Accession & AB451279, Al628974 \\
& GenBank ID & 19769225, 4665774 \\
& RefSeq & NM_130786, NM_000014 \\
& UniGene & Hs.41, Hs.56 \\
& HGNC Gene Symbol & A1BG, A1CF, A2LD1 \\
& HGNC Gene ID & 7, 8, 7645 \\
& UniProtKB Accession & P62258, Q04917 \\
& UniProtKB ID & 1433B_HUMAN \\
& PIR Accession & S34755, A61235, I38947 \\
Microarray & Affymetrix probe ID & 212073_at, 210984_x_at \\
& Illumina probe ID & 4210086, 2510484 \\
\hline
\end{tabular}

analyses are carried out at the gene level, not protein or transcript level.

\section{Datasets}

A comprehensive set of gene annotation data are integrated in the GARNET system (Table 1). The annotations are grouped into four different categories of molecular network, genome annotation, gene expression, and disease \& drug. The molecular network category consists of pathways (KEGG [15], BioCarta), protein-protein interactions (PPI) from NCBI and four major miRNA target databases (miRBase [16], TarBase [17], TargetScan [18] and PicTar [19]). The category of genome annotation contains information on gene function (Gene Ontology [20]), protein domain (Pfam [21]) and chromosomal location. Tissuespecific or cancer-related gene expression data are included in the gene expression category. We also collected gene-diesease (OMIM [22], GAD [12]) and genedrug association (DrugBank [14]) data from relevant sources, that are deposited in the disease \& drug category.

\section{User interface \\ Manager Tool}

The gene set manager tool (Manager Tool) is the main entry point to access all the annotation data and further gene set analysis in GARNET. The overall workflow is shown in Figure 2. In Manager Tool, user may create or delete a new gene set by either entering a list of gene IDs or uploading an input file. The input gene IDs are automatically converted to Entrez Gene IDs. All the

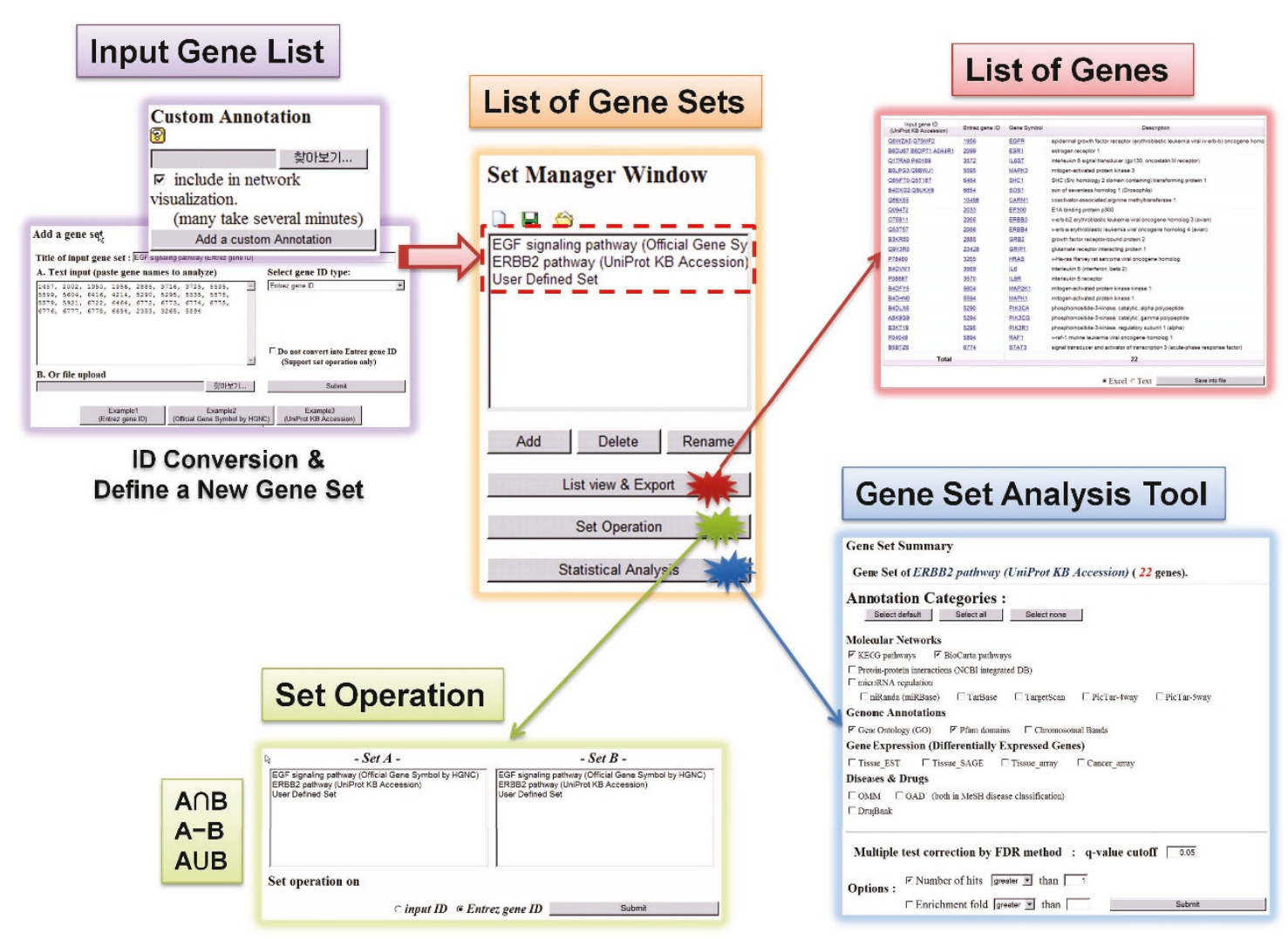

Figure 2 The gene set manager tool. 
user-created gene sets are listed up in a separate panel named Set Manager Window (dotted red box in Figure 2 ), where the gene set of interest can be chosen. Users can access the member genes of the chosen gene set or create a new gene set by set operation of existing gene sets e.g. interaction, subtraction, and union. Once gene sets are prepared in the Manager Tool, user can proceed to Analysis Tool for gene set analysis or Retrieval Tool for expanding gene list along the biological networks as described in the later sections.

\section{Analysis Tool}

Analysis Tool implements the core function of statistical over-representation analysis against various types of gene annotations. User selects a target gene set and can perform GSA against multiple types of annotations simultaneously. The overall procedure of GSA is shown in Figure 3. Kappa statistic is used as the enrichment score in GARNET. Multiple test correction is done by Benjamini-Hochberg method. The stringency of GSA is set as q-value $<0.05$ by default, but the q-value cut-off can be adjusted according to the user's preference as well as by the number of hit annotations. As a result of GSA, the list of significantly enriched annotations is displayed as table view. Particularly, the relationships among the enriched annotations are presented in an interactive network viewer. The annotation network data are downloadable in standard formats for other visualization tools (e.g. cytoscape) or network clustering softwares (e.g. MCL [23]) for further analysis. It also opens the chance to reveal connections among heterogeneous types of annotations e.g. miRNA targets and cancer signature genes, drug targets and protein. Annotations such as Gene Ontology and $\mathrm{MeSH}$ terms have hierarchical structure, which is displayed in tree view as well (top-left in Figure 3).

\section{Retrieval Tool}

Retrieval Tool is for getting the member gene list of existing annotations and for expanding the existing gene sets via various types of biological networks. For example, miRNA target genes can be expanded via

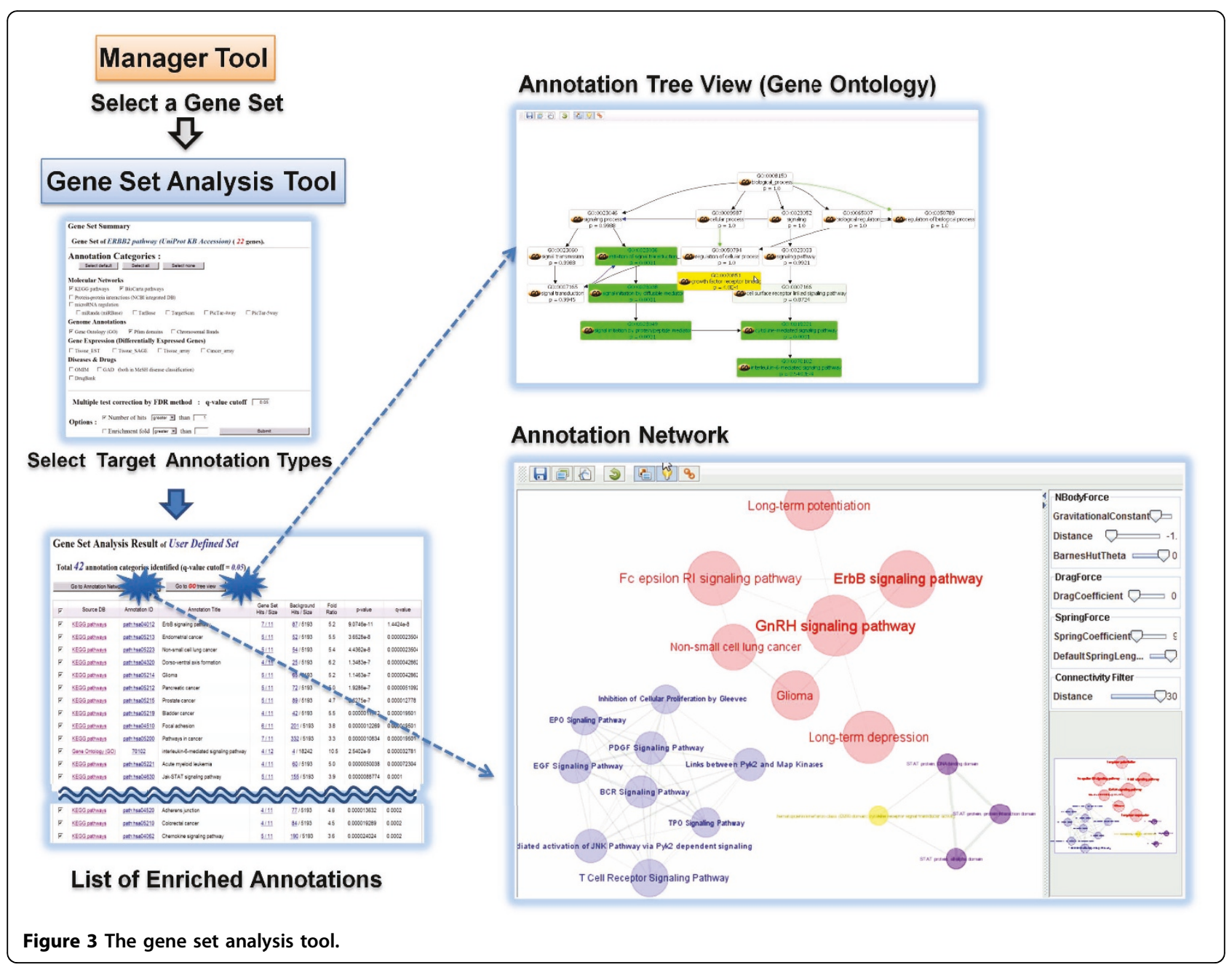


transcriptional regulatory network, and then by PPI network and so on (Figure 4). Gene set expansion via networks can be useful in combination with set operations e.g. intersection and difference in the Manager Tool, allowing a great freedom to navigate and combine the different aspects of existing knowledge. All the gene sets in GARNET is accessible by keyword or ID search and the member genes are listed in the resulting page (Figure 5).

\section{Conclusions}

GARNET (gene annotation relationship network tools) is an integrative platform for diverse types of gene set analysis, where complex relationships among gene annotations can be easily explored with an intuitive network visualization tool.

\section{Availability and requirements}

GARNET is available at http://garnet.isysbio.org/ and http://ercsb.ewha.ac.kr/garnet/.

\section{Acknowledgements}

This work was supported by "GIST Systems Biology Infrastructure Establishment Grant (2010) through Ewha Research Center for Systems Biology (ERCSB)", Biogreen 21 Program of the Korean Rural Development Administration(20070401034010) and Korea Science and Engineering Foundation (KOSEF) funded by the Korea government (MEST) (R01-2008-00020818-0 and 2007-03983).

This article has been published as part of BMC Bioinformatics Volume 12 Supplement 1, 2011: Selected articles from the Ninth Asia Pacific Bioinformatics Conference (APBC 2011). The full contents of the supplement are available online at http://www.biomedcentral.com/1471-2105/12? issue $=\mathrm{S} 1$.

\section{Author details}

${ }^{1}$ Information Center for Bio-Pharmacological Network, Seoul National University, Suwon 443-270, Korea. ${ }^{2}$ Division of Molecular Life Sciences, Ewha

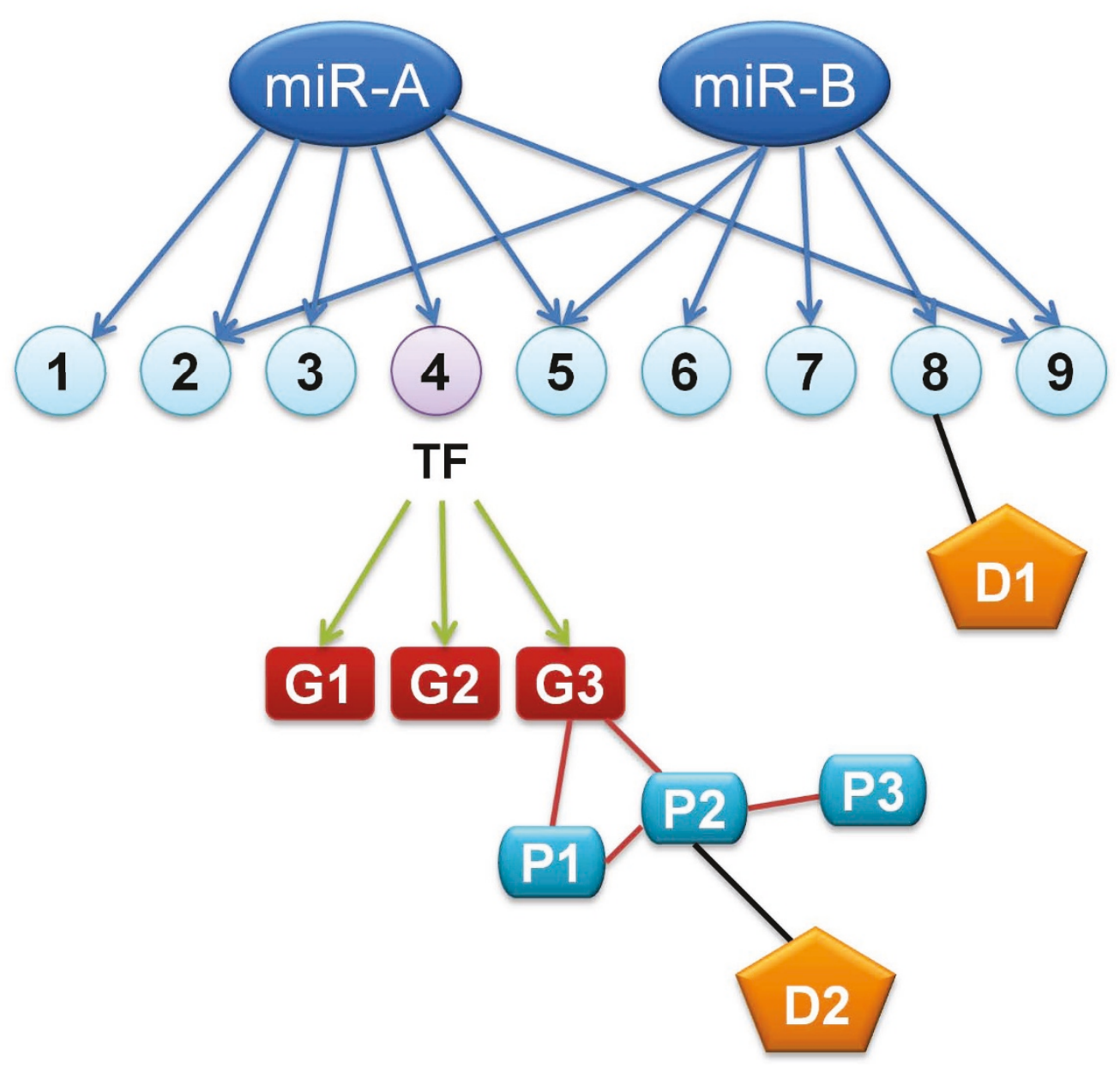

Figure 4 An example of gene set expansion via various types of biological networks. The targets of two microRNAs (miR-A and miR-B) can be expanded by transcription factor (TF)-target network (green edge) to include G1 G3. The gene set is further expanded via proteinprotein interaction network (red edge) to include P1 P3. D1 P2 and D2-8 represents Drug-target relationship (black edge). 


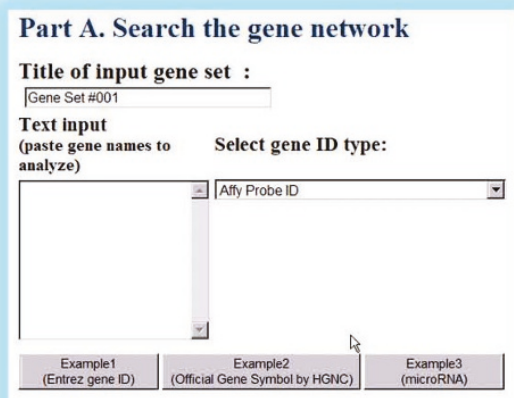

Expand by molecular networks :

F Pathway (KEGG, BioCarta)

C Transcriptional regulation (TRANSFAC)

P Protein-proten interactions (NCBI integrated DB)

microRNA regulation Show miRNA bst

$\Gamma_{\text {miRanda (mirBase) }} \quad \Gamma_{\text {TarBase }} \Gamma_{\text {Targetscan }}$

$\Gamma$ PicTar-4way Г PicTar-Sway

Options: $\subset$ up-stream $\subset$ down-stream 6 both

expansion : 17 (Maximum : 5 steps)

(The 1-step expansion means the nearest neighbor only)

Note that protem. protetin interaction is independent of direction selection.

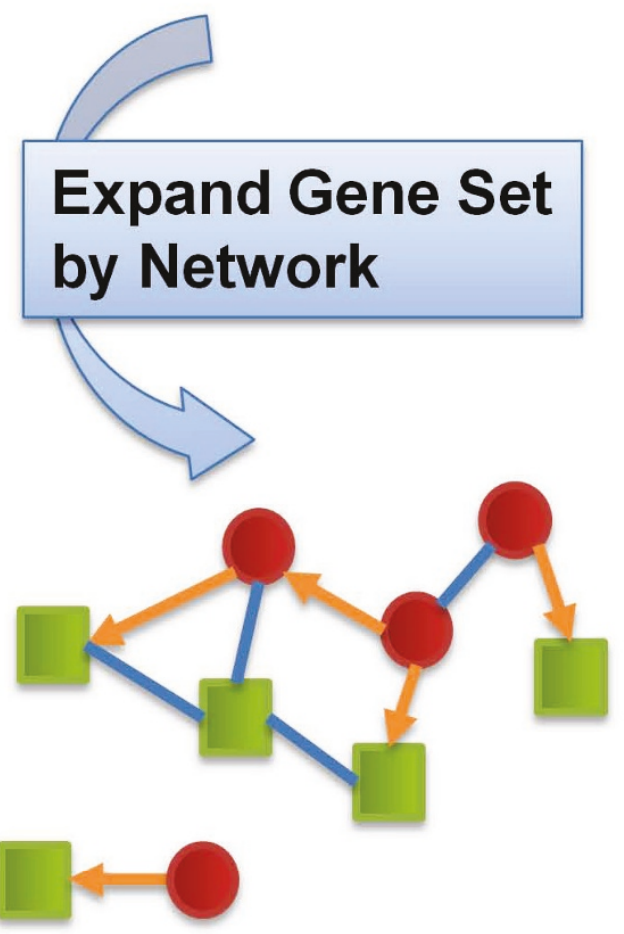

Part B. Search the annotation terms

Title of input gene set :

Gene Set $\# 001$

Annotation terms / nodes : Clear all

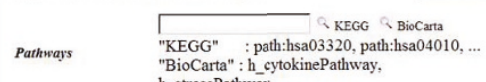
h_stressPathway,...

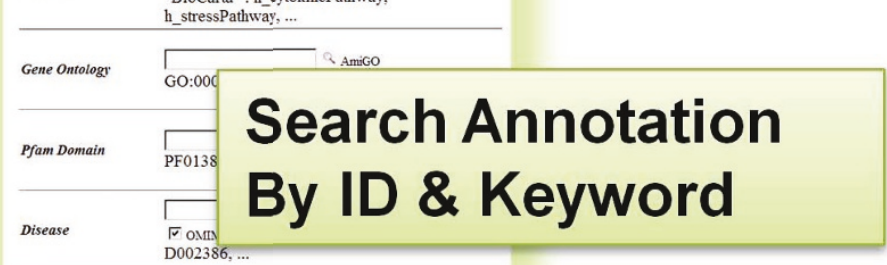

Drug $\quad \overbrace{\text { APRD00264, APRD00085, Drugank }}$

\begin{tabular}{|c|c|c|c|c|}
\hline \multirow{3}{*}{ Diff. Expression } & Data type & & Tissue: & (웡 \\
\hline & None & $\cdot$ & None & $\cdot$ \\
\hline & 6 up & & $C$ down & $r$ both \\
\hline
\end{tabular}

Chromosomal band

\section{Output Gene List}

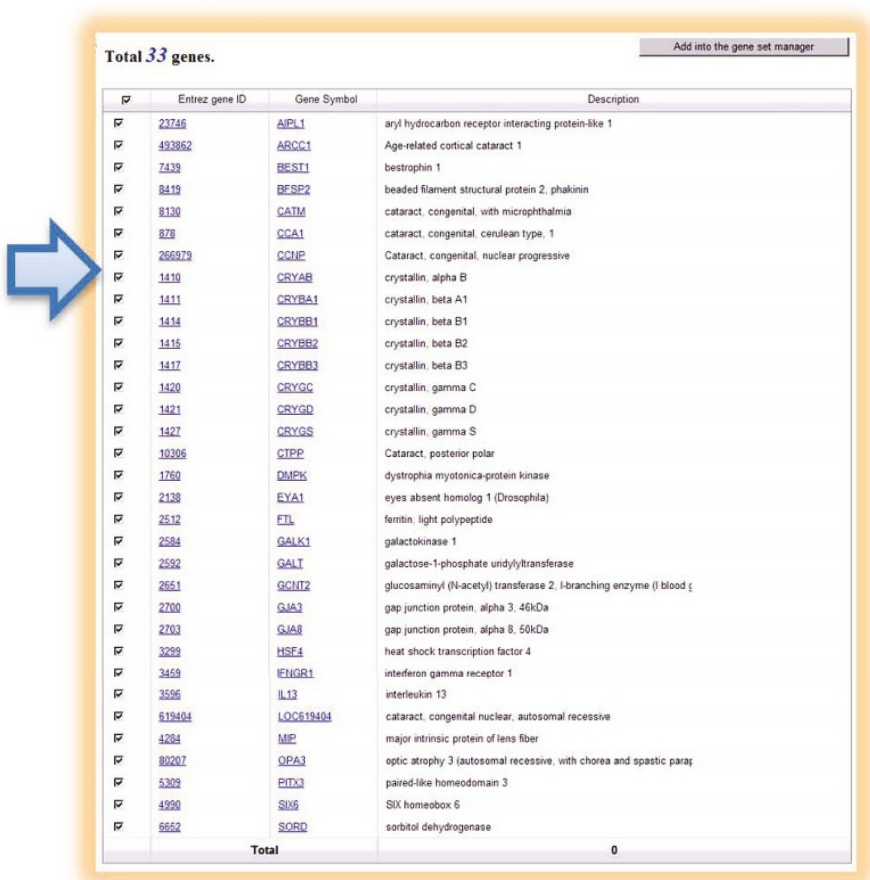


Womans University, Seoul 120-750, Korea. ${ }^{3}$ Ewha Research Center for Systems Biology (ERCSB), Ewha Womans University, Seoul 120-750, Korea. ${ }^{4}$ Center for Medicinal Protein Network and Systems Biology, College of Pharmacy, Seoul National University, Seoul 151-742, Korea. ${ }^{5}$ Cancer and Diabetes Institute, Gachon University of Medicine and Science, Incheon, 406840, Korea.

\section{Competing interests}

The authors do not have any competing interests.

Published: 15 February 2011

\section{References}

1. Subramanian A, Tamayo P, Mootha VK, Mukherjee S, Ebert BL, Gillette MA, Paulovich A, Pomeroy SL, Golub TR, Lander ES, et al: Gene set enrichment analysis: a knowledge-based approach for interpreting genome-wide expression profiles. Proceedings of the National Academy of Sciences of the United States of America 2005, 102(43):15545-15550.

2. Huang da W, Sherman BT, Tan Q, Kir J, Liu D, Bryant D, Guo Y, Stephens R, Baseler MW, Lane HC, et al: DAVID Bioinformatics Resources: expanded annotation database and novel algorithms to better extract biology from large gene lists. Nucleic acids research 2007, 35(Web Server issue): W169-175.

3. Kim SB, Yang S, Kim SK, Kim SC, Woo HG, Volsky DJ, Kim SY, Chu IS: GAzer: gene set analyzer. Bioinformatics (Oxford, England) 2007, 23(13):1697-1699.

4. Al-Shahrour F, Minguez P, Tarraga J, Medina I, Alloza E, Montaner D, Dopazo J: FatiGO +: a functional profiling tool for genomic data. Integration of functional annotation, regulatory motifs and interaction data with microarray experiments. Nucleic acids research 2007, 35(Web Server issue):W91-96.

5. Reimand J, Kull M, Peterson H, Hansen J, Vilo J: g:Profiler-a web-based toolset for functional profiling of gene lists from large-scale experiments. Nucleic acids research 2007, 35(Web Server issue):W193-200.

6. Zhang B, Kirov S, Snoddy J: WebGestalt: an integrated system for exploring gene sets in various biological contexts. Nucleic acids research 2005, 33(Web Server issue):W741-748.

7. Lachmann A, Ma'ayan A: Lists2Networks: integrated analysis of gene/ protein lists. BMC bioinformatics 11:87.

8. Tchagang AB, Gawronski A, Berube H, Phan S, Famili F, Pan Y: GOAL: a software tool for assessing biological significance of genes groups. BMC bioinformatics 11:229.

9. Huang da W, Sherman BT, Lempicki RA: Bioinformatics enrichment tools: paths toward the comprehensive functional analysis of large gene lists. Nucleic acids research 2009, 37(1):1-13.

10. Antonov AV, Schmidt T, Wang Y, Mewes HW: ProfCom: a web tool for profiling the complex functionality of gene groups identified from highthroughput data. Nucleic acids research 2008, 36(Web Server issue): W347-351.

11. Rhodes DR, Kalyana-Sundaram S, Mahavisno V, Varambally R, Yu J, Briggs BB, Barrette TR, Anstet MJ, Kincead-Beal C, Kulkarni P, et al: Oncomine 3.0: genes, pathways, and networks in a collection of 18,000 cancer gene expression profiles. Neoplasia 2007, 9(2):166-180.

12. Becker KG, Barnes KC, Bright TJ, Wang SA: The genetic association database. Nature genetics 2004, 36(5):431-432.

13. Zhang Y, De S, Garner JR, Smith K, Wang SA, Becker KG: Systematic analysis, comparison, and integration of disease based human genetic association data and mouse genetic phenotypic information. BMC medical genomics 3:1.

14. Wishart DS, Knox C, Guo AC, Cheng D, Shrivastava S, Tzur D, Gautam B, Hassanali M: DrugBank: a knowledgebase for drugs, drug actions and drug targets. Nucleic acids research 2008, 36(Database issue):D901-906.

15. Kanehisa M, Goto S, Hattori M, Aoki-Kinoshita KF, Itoh M, Kawashima S, Katayama T, Araki M, Hirakawa M: From genomics to chemical genomics: new developments in KEGG. Nucleic acids research 2006, 34(Database issue):D354-357.

16. Griffiths-Jones S, Saini HK, van Dongen S, Enright AJ: miRBase: tools for microRNA genomics. Nucleic acids research 2008, 36(Database issue): D154-158.

17. Papadopoulos GL, Reczko M, Simossis VA, Sethupathy P, Hatzigeorgiou AG: The database of experimentally supported targets: a functional update of TarBase. Nucleic acids research 2009, 37(Database issue):D155-158.
18. Lewis BP, Burge CB, Bartel DP: Conserved seed pairing, often flanked by adenosines, indicates that thousands of human genes are microRNA targets. Cell 2005, 120(1):15-20.

19. Krek A, Grun D, Poy MN, Wolf R, Rosenberg L, Epstein EJ, MacMenamin P, da Piedade I, Gunsalus KC, Stoffel M, et al: Combinatorial microRNA target predictions. Nature genetics 2005, 37(5):495-500.

20. Ashburner M, Ball CA, Blake JA, Botstein D, Butler H, Cherry JM, Davis AP, Dolinski K, Dwight SS, Eppig JT, et al: Gene ontology: tool for the unification of biology. The Gene Ontology Consortium. Nature genetics 2000, 25(1):25-29.

21. Finn RD, Tate J, Mistry J, Coggill PC, Sammut SJ, Hotz HR, Ceric G, Forslund K, Eddy SR, Sonnhammer EL, et al: The Pfam protein families database. Nucleic acids research 2008, 36(Database issue):D281-288.

22. Amberger J, Bocchini CA, Scott AF, Hamosh A: McKusick's Online Mendelian Inheritance in Man (OMIM). Nucleic acids research 2009, 37(Database issue):D793-796.

23. Enright AJ, Van Dongen S, Ouzounis CA: An efficient algorithm for largescale detection of protein families. Nucleic acids research 2002, 30(7):1575-1584.

doi:10.1186/1471-2105-12-S1-S25

Cite this article as: Rho et al:: GARNET - gene set analysis with exploration of annotation relations. BMC Bioinformatics 2011 12(Suppl 1): S25.

\section{Submit your next manuscript to BioMed Central and take full advantage of:}

- Convenient online submission

- Thorough peer review

- No space constraints or color figure charges

- Immediate publication on acceptance

- Inclusion in PubMed, CAS, Scopus and Google Scholar

- Research which is freely available for redistribution

Submit your manuscript at www.biomedcentral.com/submit
C Biomed Central 